\title{
Core Competencies for Professional Catalogers. Report of the Competencies and Education for a Career in Cataloging Interest Group Meeting. American Library Association Annual Conference, Orlando, June 2016
}

Jennifer $A$. Liss

The Competencies and Education for a Career in Cataloging Interest Group (CECCIG) provides fora for discussing the current state of education and employment in cataloging, as well as exploring the relationship of cataloging practitioners and employers with library educators (CECCIG, 2010). Years of fruitful dialogue at this intersection of cataloging education and cataloging practice bore the notion that the cataloging profession requires a core competency tool. In August 2015, the CECCIG leadership charged a Cataloging Competencies Task Force.

The Cataloging Competencies Task Force is charged to draft a core competencies document enumerating the skills and knowledge required for a career in cataloging for use by cataloging practitioners and educators. The task force will identify competencies that are broad enough to be applicable to all concerned with metadata creation, with the intent that specialized communities will extend the document in the future.

The task force will ensure that the document focuses on the foundational principals of cataloging and metadata creation and avoid recommending specific tools and standards (tools and standards may be referenced in examples, if desired). Finally, the competencies document should acknowledge catalogers' total education and careerlong development, rather than identifying a basic set of skills for new library and information science graduates (CECCIG, 2015).

At its 2016 Annual Meeting in Orlando, CECCIG co-chairs Karen Snow (Dominican University, Graduate School of Library \& Information Science) and Jennifer A. Liss (Indiana University) invited the chair of the Cataloging Competencies Task Force, Bruce J. Evans (Baylor University), to present the first draft of the document, Core Competencies for Professional Catalogers (Cataloging Competencies Task Force, 2016).

Evans gave a brief overview of the purpose of a core competencies document, the methodology used to collect potential competencies, and the structure and high-level content of the first draft. Evans then invited meeting participants to divide into small groups and discuss whether the competencies draft met the aims set out in the Task Force's charge. After thirty minutes, Snow called for each group to convey their observations.

Meeting participants were excited about the prospect of using a competencies document to support hiring, professional development, and strategic planning efforts. Participants suggested a number of use cases for the document that the Task Force had not considered, such as 
communicating needs to library and library school administrators or providing benchmarks to vendors in hopes of improving metadata quality. Participants requested clarification of the document's intended audience in the introduction.

Participants expressed a need for a roadmap to aid them through all stages in their careers. How the document could best do this (and whether the document should attempt to do so), was the subject of some debate. The draft has two sections, "Core Competencies" and "Going Beyond the Foundation." Some suggested removing the "Going Beyond" section completely, perhaps making it a separate document. Others wanted to retain the latter section but perhaps interfile the advanced competencies with the core competencies. A participant wondered if three sections could be created for early career, mid-career and late career professionals, suggesting that mid and late career competencies might lead catalogers to specializations in the field (map cataloging, database management, etc.).

Those present at the meeting had many comments on the subsection that enumerates behavioral competencies. Soft skills, for instance, could be seen as competencies for all workers and should be omitted from a document specific to catalogers. However, by leaving out any mention of soft skills, one participant wondered, would the document then suggest that soft skills aren't important or valued by the cataloguing profession? One participant noted that the multicultural sensitivity competency did not necessarily urge behaviors that foster inclusivity in the workplace amongst employees.

Participants noted unevenness in the granularity of the document. Some competencies were written too concisely; others were simply unclear. Some sections of the document appeared to receive more attention from the authors than others. When asked about the ideal level of detail for a competencies document, participants disagreed. Some appreciated the level of detail in the current draft, some wanted more detail, while others would have preferred broad statements.

The discussion of granularity dovetailed with another major point of contention with participants - whether examples should be included in the competencies document. At minimum, participants asked that examples be reviewed (there were a few obvious errors) and expanded to include examples that would be familiar to public and small libraries. Many participants argued persuasively for removing examples altogether, since examples could be seen as endorsements of certain standards, tools, or products. One participant argued that the examples could be read prescriptively by a supervisor, administrator, or dean and used to issue poor performance reviews. Possible solutions include removing the examples and appending a glossary to explain unfamiliar terms. 
In a related matter, one participant suggested that the phrase, "The list below should be considered neither prescriptive nor exhaustive," is problematic. Currently, the phrase appears in the introductions of the two major sections of the document. The phrase could be moved to the beginning of the document instead. It was noted, however, that standards, best practices, and guidelines are by nature prescriptive. Omissions, even if unintentional, may be seen as intentional editorial decisions by the authors.

A general question about how competencies documents are adopted and periodically reviewed for currency brought up the point that this document will require governance. To whom does the document belong? Should a standing committee be charged to periodically review the document?

The draft Core Competencies for Professional Catalogers, remained open for comment until July 31, 2016. The author would like to express her profound gratitude to the Task Force members, past and present CECCIG leadership, and all who commented on the draft. The CECCIG will give an update on the progress of the cataloging competencies effort at its Midwinter meeting in Atlanta.

\section{References}

CaMMS Competencies and Education for a Career in Cataloging IG (CECCIG). (2010). Retrieved from http://www.ala.org/alcts/mgrps/camms/grps/ats-ccsdgcomp

CaMMS Competencies and Education for a Career in Cataloging IG (CECCIG). (2015 August). Retrieved from http://connect.ala.org/node/247073

Cataloging Competencies Task Force. (2016 June 20). DRAFT Core Competencies for Professional Catalogers submitted for community comment. Retrieved from https://docs.google.com/document/d/1cHCaGdSEhVEban4v6BQ246k1cNn3VrYHCICFFx2D DYo/edit?usp=sharing 